\title{
PATTERNS OF MULTIMORBIDITY AMONG ELDERLY IN AN URBAN AREA OF NORTH INDIA
}

\author{
Akriti Gupta1, Sangeeta Girdhar², Anurag Chaudhary33, Jasneet Singh Chawla4, Pushapindra Kaushal ${ }^{5}$ \\ ${ }_{1}^{1}$ MBBS, Intern, Dayanand Medical College \& Hospital, Ludhiana. \\ 2Professor, Department of Community Medicine, Dayanand Medical College \& Hospital, Ludhiana. \\ 3 Professor and HOD, Department of Community Medicine, Dayanand Medical College \& Hospital, Ludhiana. \\ ${ }^{4} M B B S$, Intern, Dayanand Medical College \& Hospital, Ludhiana. \\ ${ }^{5}$ Associate Professor, Department of Community Medicine, Dayanand Medical College \& Hospital, Ludhiana.
}

\begin{tabular}{l} 
ABSTRACT \\
\hline BACKGROUND \\
Ageing is a natural process. By 2020, the number of people aged 60 years and older will outnumber children younger than 5 \\
years in the entire world. This natural phenomenon of population ageing is rampant in developing countries like India while data \\
and studies regarding health conditions and prevalence of multimorbidity is lacking.
\end{tabular}

\section{AIMS AND OBJECTIVES}

This cross sectional study was conducted to determine the morbidity pattern and health care seeking behaviour of elderly in North India.

\section{SETTINGS AND DESIGN}

Community based Cross-sectional study in Urban Field Practice Area, Shimlapuri.

\section{MATERIALS AND METHODS}

A Community based cross-sectional study was conducted in Urban field practice area, Shimlapuri under the Department of Community Medicine of Dayanand Medical College and hospital, Ludhiana, Punjab, India from June 2014 to December 2014 . The study population comprised of 534 elderlies above 60 years of age, both males and females residing in the area. The subjects were interviewed and examined in accordance with a pre-structured proforma by field workers, medical interns and faculty members. Majority of the morbidity profile was obtained through history. Information on diseases including visual impairment, respiratory diseases, musculoskeletal disorder, acid peptic disease, deafness and stroke were based on history given by the participants. The association of multimorbidity with socio demographic variables was studied.

\section{STATISTICAL ANALYSIS}

Percentages and Chi Square Test.

\section{RESULTS}

The mean age of the participants was $66.27 \pm 6.26$ years. Majority of the subjects belonged to age group of 60-69 years (70\%). Morbidity was observed in $99.5 \%$ subjects. The most common chronic condition was eye problem (68.5\%) including visual impairment and refractive error. Hypertension and acid peptic disease were found to be significantly higher among females ( $<<0.01$ ). A total of 352 study subjects (65.9\%) were found to be suffering from multimorbidity. There was significant association betwe en multimorbidity and marital status $(\mathrm{p}<0.001)$. Almost two-third of elderly belonging to middle socioeconomic status suffered from multimorbidity (p 0.0019).

\section{CONCLUSION}

This high prevalence of multimorbidity in the geriatric population calls for greater allocation of primary health care to this population subgroup. Better Preventive programs, specifically targeting the elderly should be implemented.

\section{KEYWORDS}

Elderly, Morbidity, Health Behaviour, Cross-Sectional Study.

HOW TO CITE THIS ARTICLE: Gupta A, Girdhar S, Chaudhary A, et al. Patterns of multimorbidity among elderly in an urban area of North India. J. Evolution Med. Dent. Sci. 2016;5(19):936-941, DOI: 10.14260/jemds/2016/218

\section{INTRODUCTION}

Ageing is an inescapable part of human life. In almost every country, the proportion of people aged over 60 years is growing faster than any other age group.

Financial or Other, Competing Interest: None.

Submission 23-01-2016, Peer Review 16-02-2016,

Acceptance 23-02-2016, Published 05-03-2016.

Corresponding Author:

Dr. Sangeeta Girdhar,

Professor,

Department of Community Medicine,

Dayanand Medical College \& Hospital, Ludhiana

E-mail:sangeeta_girdhar@yahoo.co.in

DOI: $10.14260 /$ jemds $/ 2016 / 218$
This population ageing can be seen as a success story for public health policies and for socioeconomic development, but it also challenges the society to adapt, in order to maximize the health and functional capacity of older people as well as their social participation and security. ${ }^{1}$ Population aging defined as a shift of population age composition towards the older ages, is a direct repercussion of decrease in fertility and increase in life expectancy. ${ }^{2}$ Between 2015 and 2050, the proportion of the world's population over 60 years will nearly double from $12 \%$ to $22 \%$. By 2020 , the number of people aged 60 years and older will outnumber children younger than 5 years. In 2050 , $80 \%$ of older people will be living in low-and middle-income countries. 
The pace of population ageing is much faster than in the past. All countries face the hurdle to ensure that their health and social systems are ready to make the most of this demographic shift. ${ }^{3}$ In India, the percentage of elderly population (60+) has gone up from 5.3 to 5.7 percent and 6.0 to 8.0 percent respectively from 1995 to 2011.4 India has thus acquired the label of "An aging Nation".

With increasing age, the pattern of diseases is also changing from communicable to non-communicable chronic diseases. These chronic diseases accumulate and present as multimorbidity in this population subgroup. Multimorbidity is defined as any combination of chronic disease with at least one other disease (Acute or chronic) or biopsychosocial factor (Associated or not) or somatic risk factor. ${ }^{5,6}$

With increasing chronic illnesses, awareness and health seeking behaviour among the elderly has increased but the delivery of health facilities at the household level has gone down due to financial constraints and increased cost of living. ${ }^{7}$ This study analyses the causes of morbidity in the elderly, from where they seek care and their average monthly expenditure. Assessment of this morbidity pattern and health seeking behaviour will help us in formulating better plans and programs and the application of these interventions in the community can improve the health status and quality of life of senior citizens.

\section{MATERIAL AND METHODS}

A community based cross sectional study was carried out in urban field practice area, Shimlapuri under the Department of Community Medicine of Dayanand medical college and hospital, Ludhiana, Punjab, India. This urban field practice area has a population of 11,257 . The study subjects included all the elderly people i.e. persons above 60 years, both male and female residing in this urban field practice area. The study was carried out from June 2014 to December 2014. Home based comprehensive health care is provided to the population of this area by multipurpose health workers under the supervision of faculty of department of Community Medicine. A folder containing information on demographic variables and other health data is maintained for each family. A list of all senior citizens was prepared from these folders. The total no. of senior citizens in the study population was 534 i.e. $4.7 \%$ of the total population of the area.

The study population (534 subjects) was interviewed by a house to house survey. Informed consent was taken from the study participants and purpose of the study was duly explained to them. The interview was based on a predesigned, pre-structured proforma. This information was collected by field workers, medical interns and faculty members. Training was given to them. The subjects were asked questions which included demographic profile, source of livelihood, morbidity profile, health care seeking behaviour, average medical expenses per month, source of these expenses and whether they adhered to the pharmacological interventions. Majority of the morbidity profile was obtained through history. Information on diseases including visual impairment, respiratory diseases, musculoskeletal disorder, psychological distress, acid peptic disease, deafness and stroke were based on history given by the participants. Subjects currently on antidiabetic and anti-hypertensive treatment were assumed to be suffering from diabetes mellitus and hypertension.
Their blood pressure was measured using a manual sphygmomanometer. Hypertension was classified according to JNC7. ${ }^{8}$ Socio-economic status was determined by using Kuppuswami scale. ${ }^{9}$ Anthropometric data regarding height and weight was also taken. The weight of the respondents was measured by using portable weighing machine which was placed horizontally on a level surface and participants were asked to stand on it without any footwear and with minimum covered clothing. The height of the participants was measured by portable stadiometer. The body mass index (BMI) was calculated as weight (In Kilograms) $\div$ height (In metre). ${ }^{2}$ Asian classification of obesity was used to classify the study population. ${ }^{10}$ Their general physical examination was also carried out to check for anaemia.

Multimorbidity was defined as any combination of chronic disease with at least one other disease (Acute or chronic) or biopsychosocial factor (Associated or not) or somatic risk factor. ${ }^{5,8}$ Chronic conditions included in the study i.e. eye problems, hypertension, respiratory diseases, musculoskeletal disorders, psychological distress, acid peptic disease, anaemia, genitourinary diseases, cognitive impairment, deafness, stroke, diabetes and dental problems. Chronic disease was defined as one lasting 3 months or more, by the definition of the United States National Centre of Health Statistics.

\section{Statistical Analysis}

The data was analyzed using SPSS 20. Chi square test was used to find the association between socio-demographic variables and multimorbidity.

\section{RESULTS}

The mean age of the participants was $66.27 \pm 6.26$ years. The demographic data of the subjects is given in Table 1 . Out of the 534 study subjects, 244 (45.7\%) were males and $290(54.3 \%)$ were females. Most (62\%) of the subjects belonged to Sikh religion, $37.4 \%$ were Hindu and $0.6 \%$ were Muslim. Majority of the subjects belonged to age group of $60-69$ years (70\%) followed by $70-79$ years $(23.2 \%)$ and only $5.8 \%$ were $>80$ years. It was observed that $45.1 \%$ of elderly were illiterate and $54.9 \%$ were literate. As per the modified Kuppuswamy scale, most of the subjects belonged to the middle socioeconomic status (56.8\%) followed by $25 \%$ to upper lower and $17.9 \%$ to the upper class. Most of the elderly were involved in household work (59.5\%). In addition, $70.6 \%$ of elderly were found to be living in a joint family as compared to $29.4 \%$ in a nuclear family. Majority of them, $(95.5 \%)$ lived in their own houses and only $4.5 \%$ lived in rented houses.

BMI was calculated for all the study subjects. Distribution of the study population according to BMI (Table 2). Almost half of the elderly (49\%) were overweight and obese while $16.7 \%$ were underweight. Morbidity was recorded in 531 subjects out of the 534 , i.e. $99.5 \%$. Only 3 senior citizens gave no history of any disease $(0.5 \%)$. Table 3 shows the occurrence of chronic conditions among the study subjects which were used for defining multimorbidity. The most common chronic condition was eye problem, (68.5\%) including visual impairment and refractive error. Other chronic diseases included hypertension (44\%), acid peptic disease (38\%) and diabetes mellitus (11\%) followed by respiratory diseases $(10 \%)$, musculoskeletal disorders $(7.5 \%)$, anaemia $(6.4 \%)$, psychological distress $(4.3 \%)$, dental problems $(2.8 \%)$, deafness $(2 \%)$ and stroke (1.4\%). 
Hypertension and acid peptic disease were found to be significantly higher among females as compared to males $(\mathrm{p}<0.01)$. Diabetes was also found to be more in females ( $p$ 0.07 ), as compared to males. There was not much difference in occurrence of other chronic diseases with respect to gender.

A total of 352 study subjects (65.9\%) were found to be suffering from 2 or more chronic conditions i.e. multimorbidity. Distribution of subjects according to the number of medical conditions is shown in the graph (Figure 4). It shows that $34.7 \%$ of the senior citizens were suffering from two chronic diseases followed by $19.8 \%$ suffering from 3 chronic illnesses, $8.2 \%$ with 4 conditions, $2.2 \%$ with five and $0.5 \%$ were found to be suffering from six chronic diseases.

Table 5 shows association of multimorbidity with age, gender, literacy, marital status, socioeconomic status, BMI and type of family. Two-third of females (75.5\%) suffered from multimorbidity as compared to males (54.5\%) and this difference was found to be highly significant $(\mathrm{p}<0.001)$. Multimorbidity showed an increasing trend with increasing age, $77.4 \%$ of the elderly above 80 years had multimorbid conditions compared to $63 \%$ in elderly belonging to $60-69$ years' age group. There was significant difference in the occurrence of multimorbity among Widows (79.2\%), unmarried $(66.7 \%)$ as compared to currently married elderly $(\mathrm{p}<0.001)$. Almost two-third of elderly belonging to middle socioeconomic status suffered from multimorbidity $(74 \%)$ as compared to upper (57.3\%) or lower class (56.7\%) and this was found to be highly significant ( $p$ 0.0019). Almost two third of elderly living in joint families $(69.7 \%)$ suffered from multimorbidity as compared to elderly living in nuclear families $(56.7 \%)$ and this association was found to be significant ( $\mathrm{p}$ 0.03).

Table 6 shows the health care seeking behaviour of senior citizens. Majority of the elderly people consulted a private doctor $(82.9 \%)$ followed by urban health centre (14.4\%), government hospital (5.4\%), registered medical practitioner $(4.1 \%)$ or dispensary $(0.7 \%)$. Majority $(74.5 \%)$ of them had average medical expenses up to 500 rupees per month and majority (95.1\%) of them adhered to their pharmacological interventions.

\section{DISCUSSION}

This community based cross-sectional study observed a very high prevalence of morbidity (99.5\%) in the study population of Urban health centre, Shimlapuri. This was found to be higher than studies carried out among elderly in Shimla (84\%). ${ }^{11}$ Chandigarh and Haryana (88.9\%). ${ }^{12}$ Northeast India (70\%).13 and Eastern India (88.5\%).14 Similar studies from other countries have reported the presence of morbidity as $84 \%$ in Bangladesh. ${ }^{5}$ and $78 \%$ in South Korea. ${ }^{15}$ This high rate of observation of morbidity in this study may be due to various factors, i.e. increased awareness by regular visits of field workers leading to increased visits to hospitals and private doctors leading to increased chances of diagnosing various chronic conditions.

The mean and median of morbidities per person was calculated to be 2.1 and 2.0 respectively, which is comparable to other studies conducted in India in which mean was 2.01 in Patiala by Singh et al. ${ }^{16}$ in 2010 and 2.6 in Amritsar by Padda et al. ${ }^{17}$ In contrast Kishore et al. ${ }^{6}$ reported a much greater number of mean morbidities (6.7) in Uttarakhand in 2015 and 3.7 in Saudi Arabia (Mohamed et al.18 in 2011). Similar to the present study, Kumar et al. ${ }^{19}$ reported prevalence of eye problems to be $63 \%$, followed by hypertension (44\%) and respiratory diseases (34\%) and Barman et al reported cataract in $61.25 \%$ and hypertension in $50.63 \%$ in a study done in Bihar. ${ }^{20}$

In contrast a study by Kokhar et al.21 dental problems were the commonest morbidity (90.62\%) followed by musculoskeletal (71\%) and visual impairment (69\%). It may be due to the reason that study was conducted among migrants. Srinivas et al. ${ }^{22}$ found diseases of Musculoskeletal System (39\%) to be most commonly seen followed by diseases of Circulatory system (21\%) and diseases of Eye and adnexa $(20 \%)$ in their study population.

The overall prevalence of multimorbidity recorded was $66 \%$. This was comparable to studies done in Odisha. ${ }^{23}$ Bangladesh. 6 and West Africa. ${ }^{24}$ which observed multimorbidity as $57 \%, 58 \%$ and $65 \%$ in the study population respectively. While another study in China by wang et al.25 in 2011 observed a much higher percentage i.e. 90\%.

Multimorbidity showed an increasing trend with increasing age. Almost two-third of elderly (77.4\%) above 80 years had multimorbid conditions compared to $63 \%$ in elderly in 60-69 years' age group. According to a meta-analysis done by Marengoni et al. ${ }^{26}$ in 2011 female gender, older age and low socioeconomic status are associated with higher multimorbidity.

Multimorbidity was higher in females (75.5\%) as compared to males $(54.5 \%)$ and this was found to be highly significant $(\mathrm{p}<0.001)$. This is in comparison to findings in another study conducted in Bangladesh by Khanam et al. ${ }^{5}$ in 2004 in which $65 \%$ females suffered from multimorbidity as compared to $39 \%$ males. As older women are more likely than older men to be unemployed, and/or widowed, and to engage in less exercise and foremost in taking care of other family members, female usually neglects her health and it can be the reason for poor health of female. In the present study almost two third of subjects belonging to middle class were having multimorbidity. A highly significant association was observed between socioeconomic status and multimorbidity $(\mathrm{p}<0.001)$.

Mental stress is also one of the risk factors for noncommunicable diseases. Multimorbidity was higher in widows (79.2\%) and unmarried (66\%) as compared to elderly living with spouse $(p<0.001)$. Loneliness may be the cause for higher occurrence of morbidity.

It was observed that $70.6 \%$ people in the study population live in joint families compared to $29.4 \%$ in nuclear families. Kishore et al. ${ }^{7}$ reported $38.1 \%$ living in joint families, rao et al. ${ }^{27} 26 \%$ in Madurai and narapureddy et al. ${ }^{28} 34 \%$ in Allahabad. The prevalence of multimorbidity was higher in joint families $(69.7 \%)$ as compared to nuclear families (56.7\%), and this was found to be statistically significant ( $\mathrm{p}$ 0.003). Indian joint families are considered to be more strong, stable, close, resilient and enduring with focus on family unity. ${ }^{29}$ This could be due to the reason that almost $90 \%$ of elderly aged more than 75 years were residing in joint family and morbidity increases with increase in age.

\section{CONCLUSION}

Majority of the elderly suffered from some form of morbidity and more than half of them suffered from multimorbidity. This proves that clinicians and researchers should put in special efforts to diagnose multimorbidity in senior citizens. More female elderly suffer from multimorbidity, hence such risk 
factors should be kept in mind while looking after elderly.

Primary health care should be made more approachable for the senior citizens. Preventive health care strategies and programs specific to the need of the elderly should be formulated and implemented. The geriatric population requires special attention for overall development of the society.

\begin{tabular}{|c|c|}
\hline \multicolumn{2}{|c|}{ Demographic Variable } \\
\hline Gender & \\
\hline Male & $244(45.7 \%)$ \\
\hline Female & $290(54.3 \%)$ \\
\hline Religion & \\
\hline Hindu & $200(37.4 \%)$ \\
\hline Sikh & $331(62 \%)$ \\
\hline Muslim & $3(0.6 \%)$ \\
\hline Age (In years) & \\
\hline $60-69$ & $379(70.9 \%)$ \\
\hline $70-79$ & $124(23.2 \%)$ \\
\hline$>80$ & $31(5.8 \%)$ \\
\hline Marital Status & \\
\hline Currently married & $332(62.1 \%)$ \\
\hline Unmarried & $03(0.5 \%)$ \\
\hline Widow & $154(28.3 \%)$ \\
\hline
\end{tabular}

\begin{tabular}{|c|c|}
\hline Widower & $45(8.4 \%)$ \\
\hline Education & \\
\hline Illiterate & $241(45.1 \%)$ \\
\hline Literate & $293(54.9 \%)$ \\
\hline Socio economic status & \\
\hline Upper & $96(17.9 \%)$ \\
\hline Upper middle & $123(23 \%)$ \\
\hline Middle & $181(33.8 \%)$ \\
\hline Upper lower & $134(25.09 \%)$ \\
\hline Occupation & $134(25.09 \%)$ \\
\hline Working & $64(11.9 \%)$ \\
\hline Retired & $18(3.3 \%)$ \\
\hline Business & $318(59.5 \%)$ \\
\hline Household work & \\
\hline Table 1: Demographic Data of study subjects (N= 534) \\
\hline
\end{tabular}

\begin{tabular}{|c|c|}
\hline Category & N (\%age) \\
\hline Underweight $(<18.5)$ & $89(16.7 \%)$ \\
\hline Normal $(18.5-22.9)$ & $183(34.3 \%)$ \\
\hline Overweight $(23-24.9)$ & $86(16.1 \%)$ \\
\hline Obese ( 225$)$ & $176(32.9 \%)$ \\
\hline \multicolumn{2}{|c|}{ Table 2: Distribution of subjects } \\
according to BMI $\left(\mathbf{k g} / \mathbf{m}^{2}\right)$
\end{tabular}

\begin{tabular}{|c|c|c|c|c|c|c|c|}
\hline \multirow{3}{*}{$\begin{array}{c}\text { Medical Condition } \\
\text { Eye problems }\end{array}$} & \multicolumn{2}{|c|}{$\mathrm{N}=534$} & \multirow{2}{*}{\multicolumn{2}{|c|}{$\begin{array}{c}\text { Males (\%) } \\
n=244\end{array}$}} & \multirow{2}{*}{\multicolumn{2}{|c|}{$\begin{array}{c}\text { Females (\%) } \\
n=290\end{array}$}} & \multirow{3}{*}{$\begin{array}{r}\text { p-value } \\
0.2758\end{array}$} \\
\hline & \multirow{2}{*}{$\begin{array}{c}\text { Number } \\
364\end{array}$} & \multirow{2}{*}{\begin{tabular}{|c|} 
\%age \\
68.1
\end{tabular}} & & & & & \\
\hline & & & 167 & 68.4 & 211 & 72.7 & \\
\hline Hypertension & 235 & 44 & 94 & 38.5 & 158 & 54.4 & $<0.001$ \\
\hline Respiratory diseases & 56 & 10.4 & 26 & 10.6 & 37 & 12.7 & 0.4530 \\
\hline Musculoskeletal disorders & 40 & 7.5 & 18 & 7.3 & 23 & 7.9 & 0.8107 \\
\hline Psychological distress & 23 & 4.3 & 12 & 4.9 & 11 & 3.7 & 0.5236 \\
\hline Acid peptic disease & 206 & 38.6 & 81 & 33.2 & 139 & 51.7 & $<0.001$ \\
\hline Anaemia & 34 & 6.4 & 13 & 5.3 & 15 & 5.1 & 0.9360 \\
\hline Genitourinary diseases & 1 & 0.2 & 0 & 0 & 2 & 0.6 & 0.2333 \\
\hline Cognitive impairment & 4 & 0.75 & 1 & 0.4 & 3 & 1.0 & 0.4043 \\
\hline Deafness & 11 & 2.0 & 4 & 1.6 & 10 & 3.4 & 0.1928 \\
\hline Stroke & 8 & 1.4 & 3 & 1.2 & 5 & 1.7 & 0.6393 \\
\hline Diabetes & 59 & 11 & 26 & 10.6 & 46 & 15.9 & 0.0793 \\
\hline Dental problems & 15 & 2.8 & 5 & 2.0 & 9 & 3.1 & 0.4475 \\
\hline & & $M$ & 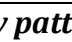 & studv & & & \\
\hline
\end{tabular}

*multiple responses obtained

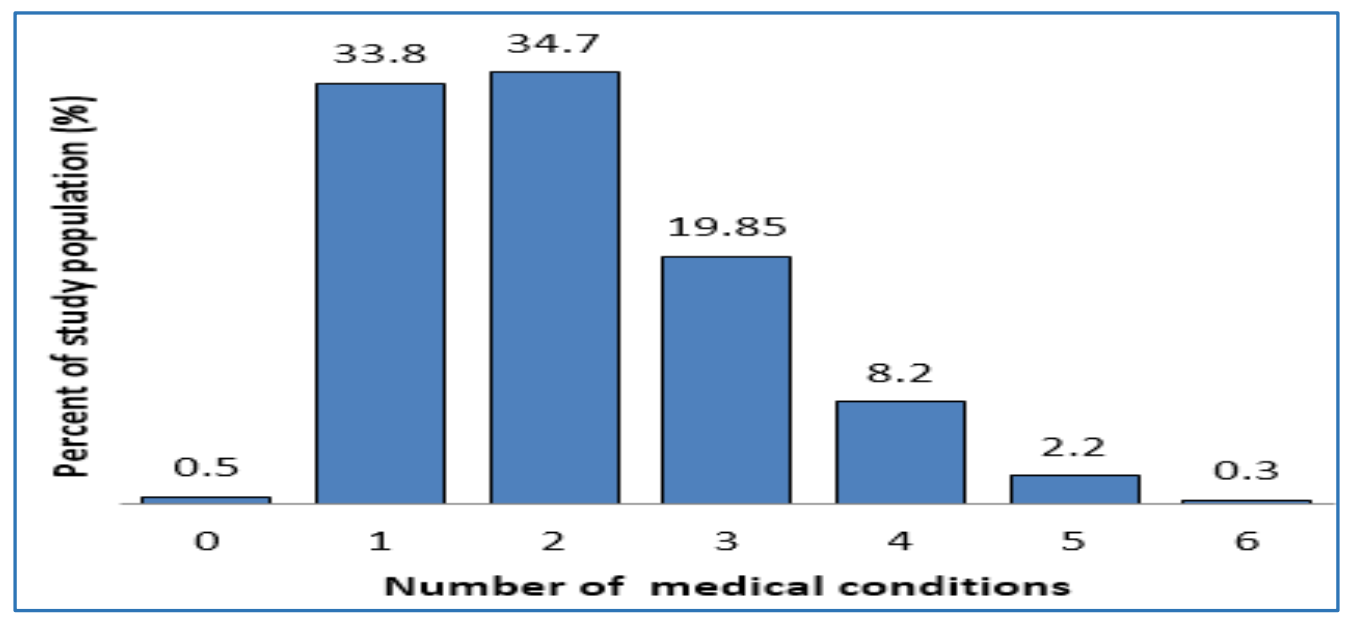

Fig. 1: Distribution of Medical Conditions among Study Subjects 


\begin{tabular}{|c|c|c|c|c|c|c|c|}
\hline \multirow{2}{*}{$\begin{array}{c}\text { Demographic Variable } \\
\text { Age (Years) } \\
\end{array}$} & \multicolumn{2}{|c|}{ Total (\%) } & \multicolumn{2}{|c|}{$\begin{array}{c}\text { Multimorbid } \\
\text { Conditions Present } \\
(\mathrm{N}=352)\end{array}$} & \multicolumn{2}{|c|}{$\begin{array}{c}\text { Only One } \\
\text { Condition Present } \\
(\mathrm{N}=182)\end{array}$} & \multirow[t]{2}{*}{$P$ value } \\
\hline & $\mathbf{N}$ & $\%$ Age & $\mathbf{N}$ & $\%$ Age & $\mathbf{N}$ & $\%$ Age & \\
\hline $60-69$ & 379 & 70.9 & 239 & 63 & 140 & 36.9 & 0.07826 \\
\hline $70-79$ & 124 & 23.2 & 89 & 71.77 & 35 & 28.2 & \\
\hline$\geq 80$ & 31 & 5.8 & 24 & 77.4 & 07 & 22.5 & \\
\hline \multicolumn{8}{|l|}{ Gender } \\
\hline Male & 244 & 45.7 & 133 & 54.5 & 111 & 45.5 & $<0.0001$ \\
\hline Female & 290 & 54.3 & 219 & 75.5 & 71 & 24.5 & \\
\hline \multicolumn{8}{|l|}{ Literacy } \\
\hline Illiterate & 241 & 45.1 & 158 & 65.5 & 83 & 34.4 & 0.8744 \\
\hline Literate & 293 & 54.8 & 194 & 66.2 & 99 & 33.8 & \\
\hline \multicolumn{8}{|l|}{ Marital status } \\
\hline Currently Married & 332 & 62.1 & 201 & 60.5 & 131 & 39.5 & $<0.001$ \\
\hline Unmarried & 03 & 0.5 & 02 & 66.7 & 01 & 33.3 & \\
\hline Widow & 154 & 28.3 & 122 & 79.2 & 32 & 20.77 & \\
\hline widower & 45 & 8.4 & 27 & 60 & 18 & 40 & \\
\hline \multicolumn{8}{|l|}{ Socio-economic status } \\
\hline Upper & 96 & 17.9 & 55 & 57.29 & 41 & 42.7 & 0.0019 \\
\hline Upper middle & 123 & 23 & 87 & 70.7 & 36 & 29.2 & \\
\hline Middle & 181 & 33.8 & 134 & 74 & 47 & 25.9 & \\
\hline Upper lower & 134 & 25 & 76 & 56.7 & 58 & 43.3 & \\
\hline \multicolumn{8}{|l|}{ BMI } \\
\hline Underweight & 89 & 16.6 & 61 & 68.5 & 28 & 31.5 & 0.9169 \\
\hline Normal & 183 & 34.2 & 119 & 65.0 & 64 & 35 & \\
\hline Overweight & 86 & 16.1 & 55 & 63.9 & 31 & 36.1 & \\
\hline Obese & 176 & 32.9 & 117 & 66.4 & 59 & 33.6 & \\
\hline \multicolumn{8}{|l|}{ Type of family } \\
\hline Nuclear family & 157 & 29.4 & 89 & 56.7 & 68 & 43.3 & 0.003 \\
\hline Joint family & 377 & 70.6 & 263 & 69.7 & 114 & 30.2 & \\
\hline
\end{tabular}

\begin{tabular}{|c|c|}
\hline Health Facility ${ }^{\dagger}$ & N (\% Age) \\
\hline Dispensary & $4(0.7 \%)$ \\
\hline Government hospital & $29(5.4 \%)$ \\
\hline Urban health centre & $77(14.4 \%)$ \\
\hline Private doctor & $443(82.9 \%)$ \\
\hline Registered medical practitioner & $22(4.1 \%)$ \\
\hline \multicolumn{1}{|c|}{ Average Medical Expenses Per Month } \\
\hline Upto Rs. 500 & $398(74.5 \%)$ \\
\hline 1001-1000 & $112(20.9 \%)$ \\
\hline $1501-2000$ & $23(4.3 \%)$ \\
\hline Yes & $1(0.2 \%)$ \\
\hline No & $508(95.1 \%)$ \\
\hline & $26(4.9 \%)$ \\
\hline
\end{tabular}

†multiple responses obtained

\section{REFERENCES}

1. World health organization. Ageing [Internet] cited Jan 6, 2016. Available from:

http://www.who.int/topics/ageing/en/

2. Philipov D, Goujon A, Di Giulio P. Ageing dynamics of a human-capital-specific population. Demographic Research 2014;31:1311-36.

3. World health organization. Disability and health [Internet] cited Jan 6, 2016, Available from: http://www.who.int/mediacentre/factsheets/fs352/en/

4. Census of India. Office of the Registrar General \& Census Commissioner, India. [Internet] Cited Jan 6 2016, 2011. Available from:
http://www.censusindia.gov.in/vital_statistics/SRS_Repo rt/9Chap\%202\%20-\%202011.pdf

5. Khanam M, Streatfield P, Kabir Z, et al. Prevalence and patterns of multimorbidity among elderly people in rural bangladesh: a cross-sectional study. J Health Popul Nutr 2011;29(4):406-14.

6. The world health report primary health care (Now More Than Ever). [Internet]. cited 6 January 2016, 2008. Available from: http://www.who.int/whr/2008/en/

7. Kishore S, Sharma K, Singh R, et al. Chronic morbidity and health care seeking behaviour amongst elderly population in rural areas of Uttarakhand. Indian J Community Health 2015;27(2):252-56. 
8. Chobanian A, Bakris G, Black H, et al. Seventh report of the joint national committee on prevention, detection, evaluation, and treatment of high blood pressure. Hypertension 2003;42(6):1206-52.

9. Bairwa M, Rajput M, Sachdeva S. Modified kuppuswamy's SES scale: social researcher should include updated income criteria, 2012. Indian J Community Med 2013;38(3):185-6.

10. World health organization (WHO), International association for the study of obesity (IASO), and international obesity task force (IOTF). The asia-pacific perspective: redefining obesity and its treatment. Geneva: World health organization 2000:378-420.

11. Sharma D, Mazta S, Parashar A. Morbidity pattern and health-seeking behavior of aged population residing in Shimla hills of North India: A cross-sectional study. J Fam Med Primary Care 2013;2(2):188-193.

12. Joshi K, Kumar R, Avasthi A. Morbidity profile and its relationship with disability and psychological distress among elderly people in Northern India. Int J Epidemiol 2003;32(6):978-87.

13. Ghosh A, Singh A. Health status of elderly in a rural area of north east region of India. Nat J Community Med 2014;5(2):236-39.

14. Shankar R, Tondon J, Gambhir I, et al. Health status of elderly population in rural area of Varanasi district. Indian journal pf public health [Internet] cited Jan 6 2016, 2007;51(1):56-58. Available from: http://www.ncbi.nlm.nih.gov/pubmed/18232146/

15. Woo E, Han C, Jo S, et al. Morbidity and related factors among elderly people in South Korea: results from the Ansan Geriatric (AGE) cohort study. BMC Public Health 2007;7(1):10.

16. Singh N, Singh S, Yadav A, Suman S, Kumar S, Singh J. Community-based study of the morbidity profile among elderly people in a rural area of Patiala district. Journal of Advance Researches in Biological Sciences [Internet]. cited Jan 8 2016, 2012;4(2):156-61. Available from: http://www.scopemed.org/fulltextpdf.php?mno=30141

17. Padda A, Mohan V, Singh J, et al. Health profile of aged persons in urban \& rural field practice areas of medical college, Amritsar. Indian Journal of Community Medicine 1998;23(2):72-76.

18. Hassanien N, Jabloun C, Al-Modeer M. Profile of morbidity among elderly at home health care service in Southern Saudi Arabia. J Fam Community Med 2013;20(1):53-57.
19. Ashok Kumar T, Sowmiya KR, Radhika G. Morbidity pattern among the elderly people living in a southern rural India-a cross sectional study. Nat J Res Com Med 2012;1(1):1-60.

20. Barman S, Lata K, Ram R, et al. A study of morbidity profile of geriatric population in an urban community of Kishanganj, Bihar, India. Global journal of Medicine and Public health [Internet] cited 2016 Jan 8, 2014;3(1). Available from: http://www.gjmedph.org/uploads/01Vo3No1.pdf

21. Khokhar A, Mehra M. Life style and morbidity profile of geriatric population in an urban community of Delhi. Indian J Med Sci 2001;55(11):609-15.

22. Srinivas PJ , Manjubhashini S. A study on morbidity profile among elderly population in Visakhapatnam District, Andhra Pradesh. Journal of Dental and Medical Sciences 2014;13(9):21-25.

23. Banjare P, Pradhan J. Socio-economic inequalities in the prevalence of multi-morbidity among the rural elderly in Bargarh District of Odisha (India). PLoS ONE 2014;9(6):e97832.

24. Hien H, Berthe A, Drabo M, et al. Prevalence and patterns of multimorbidity among the elderly in Burkina Faso: cross-sectional study. Trop Med Int Health 2014;19(11):1328-1333.

25. Wang R, Yan Z, Liang Y, et al. Prevalence and patterns of chronic disease pairs and multimorbidity among older chinese adults living in a rural area. PLOS ONE 2015;10(9):e0138521.

26. Marengoni A, Angleman S, Melis R, et al. Aging with multimorbidity: a systematic review of the literature. Ageing Research Reviews 2011;10(4):430-439.

27. Rao AV, Madhavan T. Gerospsychiatric morbidity survey in a semi-urban area near madurai. Indian J Psychiatry 1982;24(3):258-67.

28. Narapureddy B, Naveen KH, Madithati P, et al. Sociodemographic profile and health care seeking behaviour of rural geriatric population of Allahabad district of UP: A cross sectional study. Int J Med Sci Public Health 2012;1(2):87-92.

29. Mullatti L. Families in India: beliefs and realities. J Comp Fam Stud 1995;26:11-25. 